\section{Aspectos pré-históricos pleistocênicos do projeto arqueológico Manguinhos e suas potencialidades}

Maria da Conceição de Moraes Coutinho Beltrâo*

\section{INTRODUÇĀO}

O Projeto "Sítios Pré-históricos e Megafauna Extinta no Brasil", coordenado pela autora da presente comunicação, relaciona-se a sítios arqueológicos que por sua antiguidade são indiscutivelmente contemporâneos de uma fauna de grande porte (megafauna) que se extinguiu há cerca de 11.000 anos, isto é, no fim do pleistoceno ou no iníco do holoceno.

Os sítios arqueológicos, objeto de nossos estudos intensivos, dentro do projeto em causa, podem ser grupados cronologicamente em:

19) Sítios do Pleistoceno Superior (situados entre 11.000 e 130.000 de anos como, por exemplo o sítio Alice Boër - SP).

2.) Sítios do Pleistoceno Médio (situados entre 130.000 e 1.000 .000 anos como os de Itaboraí e Manguinhos - RJ e Toca de Esperança - BA).

O sítio arqueológico de Manguinhos foi descoberto em 1966. Na ocasião, em um corte de estrada, na área do Instituto Oswaldo Cruz, foi verificada a existência de vestígios de duas ocupações holocênicas, is to é, de menos de 11.000 anos. Uma delas correspondente a uma ocupação Tupi-Guarani (Tupinambá), situada provavelmente dentro da faixa cronológica de 500 d.C. a 1.500 d.C.. A outra, também Tupinambá, correspondente ao aldeamento de Payó, registrado por Jean de Léry em 1557.

Manguinhos foi "re-descoberto" por Bel trão em 1986, isto é, 20 anos dépois da descoberta da aldeia e do aldeamento Tupinambá, quando verificou a existência de ocupações pleistocênicas muito mais antigas.

Os materiais arqueológicos dessa época pleistocênica são constituídos, essencialmente, por uma indústria lítica cuja matéria-prima é, de modo geral, quartzo. Eles existem sob a forma de artefatos nas camadas IV e VI. Os ossos e dentes de Equus encontrados na camada VI deixam em aberto a possibilidade de tratar-se de animal da mesma época, entre outras razões pelo fato do animal não apresentar fraturas recentes. Não está excluída a possibilidade de se tratar

* Arqueóloga do Museu Nacional do Rio de Janeiro 
de um Equus do período histórico - que teria sido utilizado nas experiências do Instituto Óswaldo Cruz - e que também teria sido, de alguma maneira, introduzido na camada pleistocênica, isto $\varepsilon$, de mais de 11.000 anos. Dois fragmentos ósseos e um dente (molar) desse cavalo fóssil (?) foram enviados ao Institut Dolomieu, em Grenoble, para dataçāo pelo método de Ressonância Paramagnética Eletrônica, a cargo do Dr. Gerárd Poupeau, sob supervisão técnica do Dr. Jacques Danon.

Independentemente do Equus ser antigo ou recente, os artefatos líticos encontrados nas camadas IV e VI, comprovam indiscutivelmente, uma ocupação humana pleistocênica em Manguinhos.

\section{LOCALIZAÇĀO}

O sítio arqueológico de Manguinhos está situado dentro da área onde está sediado o Instituto Oswaldo Cruz, na Av.Brasil, 4365, na cidade do Rio de Janeiro.

\section{PROSPECÇÕES E ESCAVAÇÕES}

Depois de várias prospecçōes nas superficies colinosas, encontradas dentro dos limites do Instituto Oswaldo Cruz, optamos, inicialmente, por escavar naquela onde se situa a Casa Amarela.

Essa elevação é constituída por camadas coluvionais quaternárias que podem atingir vários metros de altura.

Num dos bordos da colina onde há hoje uma creche, na camada correspondente a um antigo mangue: por ocasião do aplainamento do terreno, feito por trator, foram encontrados os ossos e dentes do Equus, já referido (Equus existiram no Brasil há muitas dezenas de milhares de anos, tendo-se extinguido há uns 11.000 anos. Foi, posteriormente, reintroduzido pelos europeus).

As camadas de mangue, quando contêm restos de ocupação humana, são, de modo geral, de vital importância para 0 arqueólogo porque costumam preservar bem os materiais orgânicos. Aliás, entre os materiais orgânicos passíveis de serem encontrados neste tipo de camada existente em Manguinhos, alguns poderáo se transformar em objeto de estudo no Instituto Oswaldo Cruz, desde que se encaixem na constelação de técnicas de pesquisa, tradicionalmente executadas pela instituição.

\section{ASPECTOS MORFO-ESTRATIGRÁFICOS}

Os sítios pré-históricos de Manguinhos estão localizados em superficies colinosas de encosta - "rampa" - pouco íngremes.

As vertentes prospectadas apresentaram nas camadas superficiais uma seqüência de coluvios com, 
pelo menos, uma linha de seixos composta de fragmentos subangulosos de quartzo (cascalheira). gional.

Essa cascalheira tem importante significado re-

A litologia da cascalheira permite inferir que ela se formou sob condiçōes torrenciais, embora os seixos e fragmentos de quartzo não devam ter sido carregados muito longe da área fonte.

O clima à época da formação da cascalheira deve ter sido semi-árido.

A estratigrafia dessas superficies colinosas, em Manguinhos, reflete as fases erosivas e de sedimentação do Quatemário.

Como Itaboraí (vide "Relatório de Atividades: Itaborai"), Manguinhos tem condiçōes de se transformar em sítio de referência. Não só pode vir a contribuir para a determinação da idade de outros sítios arqueológicos localizados em "rampas", como para vir a subsidiar a interpretação geocronológica de cascalheiras registradas em vários pontos do Brasil Meridional.

Há, portanto, necessidade de trabalho conjugado do arqueólogo com o geomorfólogo para permitir a busca de um melhor equacionamento da dinâmica paleoambiental na área em estudo.

Elaboramos uma cronoestratigrafia preliminar para entender melhor as relaçōes estratigráficas do sítio.

Cronoestratigrafia (provisória)

\begin{tabular}{|c|c|c|c|}
\hline I. & Camada húmica & periodo histórico recente & Instalaçäo de Manguinhos. \\
\hline II. & Camada coluvial & perfodo historico antigo & $\begin{array}{l}\text { Faz, do Sec. X VIII aldeamento } \\
\text { Tupinamba (SEc. XVI). }\end{array}$ \\
\hline III. & Camada oluvial & perlodo prethistórico & $\begin{array}{l}\text { A ldeia Tupinamba (de idade situa- } \\
\text { da entre } 500 \text { e } 1.500 \text { d.C. - ocu- } \\
\text { paçăo holocinica. }\end{array}$ \\
\hline IV*. & Camada de cascalho & período pré-histórico & $\begin{array}{l}\text { Ocupaçäo do Pleistoceno MEdio } \\
\text { (130 mil a I milhăo de anos) arte- } \\
\text { fatos líticos. }\end{array}$ \\
\hline $\mathrm{V}^{*}$. & Camada oluvial arenosa & perfodo prethistórico & $\begin{array}{l}\text { Pleistoceno Superior ( } 130 \text { mil a } \\
11 \text { mil anos). Nâ foram ainda } \\
\text { achados artefatos. }\end{array}$ \\
\hline VI*. & Camada de mangue fóssil & perfodo pré-hist6rico & $\begin{array}{l}\text { Ocupaçāo do Pleistoceno Superior } \\
\text { (130 mil a } 11 \text { mil anos) - artefatos } \\
\text { líticos. }\end{array}$ \\
\hline
\end{tabular}

(*) - Há uma aparente inversāo da estratigrafia, ficando a camada IV, mais velha, acima das camadas mais recentes, V e VI, fato este que está de acordo com o modelo de retrabalhamento do colávio proposto por Moura e Meis (1980).

Cadernos de Saúde Pública, RJ, 5 (1): 121-128, jan/mar, 1989 
A seqüência estratigráfica de Manguinhos é composta de, pelo menos, 6 camadas bem nítidas. Uma delas é constituída por uma camada de seixos e fragmentos de quartzo onde existem numerosos artefatos pleistocênicos. Além dessa há artefatos pleistocênicos na camada correspondente ao antigo mangue.

\section{ARTEFATOS}

O homem pré-histótico já encontrou no local, a matéria-prima que mais utilizou no sítio aí localizado: quartzo.

Esta matéria-prima, apesar de não ser de tão boa qualidade quanto o sílex, foi tratada, em alguns casos, com grande habilidade. Assim, a técnica de preparação do núcleo por lascamento circundante (que existe em Itaboraí sobre sílex) foi aplicada em Manguinhos sobre o quartzo. Há ainda, lascas orientadas, em quartzo, com bordos paralelos transformados em raspadores.

A relação dos artefatos líticos até agora encontrados, embora não seja muito grande, em virtude de estarmos apenas iniciando os trabalhos de escavação, é muito expressiva. Inclui: choppers, facas e raspadores de vários tipos, inclusive os raspadores laterais em lasca espessa etc. Há também vários núcleos que permitirão a reconstituição das técnicas empregadas na confecção dos objetos.

$\mathrm{Na}$ camada de mangue, que aparentemente corresponde ao Pleistoceno Superios $(130 \mathrm{mil}$ anos a 11 mil) a pátina dos artefatos é pouco visível, porque aí os materiais foram sempre lavados pela umidade constante da camada.

$\mathrm{Na}$ cascalheira, que pertence, como idade, ao Pleistoceno Médio, a pátina é conspícua, brilhante e de modo geral amarelada.

Há nos artefatos encontrados na cascalheira de Manguinhos, uma grande identidade tipológica com os artefatos das cascalheiras do sítio arqueológico de Itaboraí. Aliás, o sítio de Itaboraí in tegra o que definios como a Região Arqueológica de Manguinhos.

\section{SINGULARIDADE DO SÍTIO}

O sítio arqueológico de Manguinhos singulariza-se pela sua incomum abrangência temporal.

A cronologia da ocupação inicia-se por faix as bastante recuadas, como o Pleistoceno Médio (portanto, há, pelo menos, 130 mil anos, na faixa cronológica correspondente ao Homo erectus) passa por várias ocupaçōes situadas em faixas mais recentes, como a que corresponde ao antigo mangue (do Pleistoceno Superior), alcança ocupaçōes Tupinambá dos períodos proto-históricos e históricos, atinge uma fazenda do séc. XVIII para, significativamente, desembocar, já nesse 
século, na instalação, no local, de um monumento da pesquisa científica no Brasil, que é o Instituto Oswaldo Cruz.

JUSTIFICATIVAS PAlLA ESCOLILAE dAS AHES DE PROSPECAU

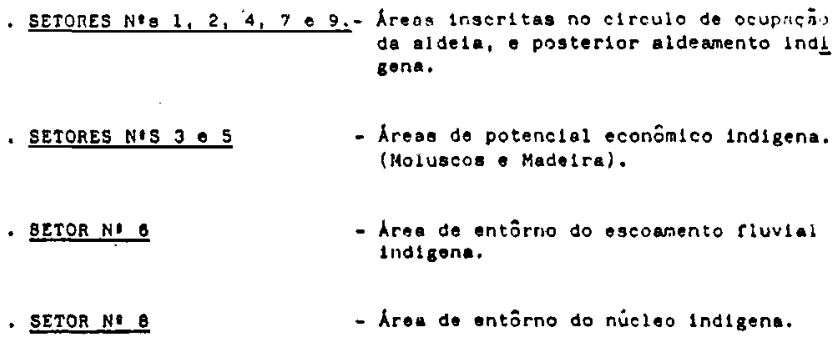

- setor ni

- Arou de entârno do núeloo indigena.

\begin{tabular}{|c|c|c|}
\hline & & SUPERPOSICKO DAS DCUPACZOES HUMANAS \\
\hline H & $\begin{array}{l}\text { SÉculo } \\
x x\end{array}$ & NOCLLEO CONSOLIDADO \\
\hline 8 & $\begin{array}{l}\text { stcuLos } \\
x \vee I X X I X\end{array}$ & TORMAĊZO DO NÚCLEO URBANO \\
\hline E & 1.500 & MOLENTO DE CONTACTO \\
\hline 8 & PEAFODOS & GRUPOS EM PROCESSO OE SEOENTARIZACGA \\
\hline 䨔 & $\begin{array}{c}\text { NITERIORES } \\
\mathbf{A} \\
1.500\end{array}$ & $\begin{array}{l}\text { GRUPOS CACADORES } \\
\text { GRANDE ANTICUIOADE }\end{array}$ \\
\hline
\end{tabular}

CONFIRIAACOES

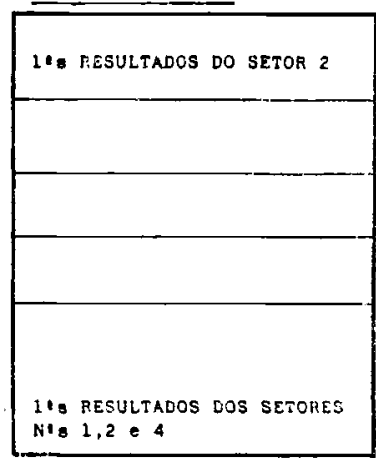

CAMADAS ESTRATIGRAFICAS

\section{CAMADA 4}

Incldêncie de arteratoe $11 t 1000$ em quartzo epresentendo pítine coneplcua, brilinante. enareloda. PEArodo! plelatoceno médio. (sETOREs 1 e 2 ).

\section{CAMADA 5}

Näo tendo apreaentado, por enquanto, artefa tos $11 t 1 \mathrm{COB}$.

PERIODO: pleistocono suporior. (SETOR 4),

\section{CAMADA 6}

Incldêncta de artefatos liticos en quartzo. epresentando patna pouco visivél associados - matorial óseo, enaligados identlfica-l doa como pertencentes eo Eqque. (IETor 4) ple 1 toceno ouperior.

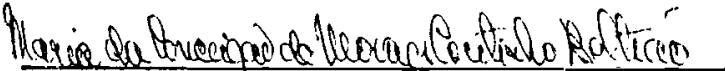

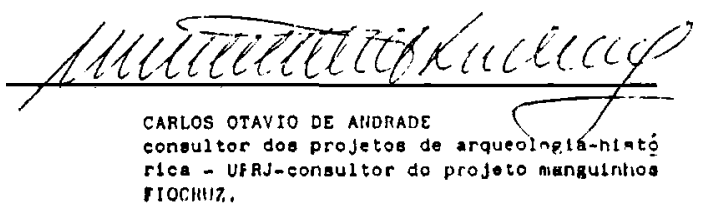

MARIA DA CONCEZCZOO BELTRÃO

profesgore titular de arqueologia - UFRJ, coordenadora do projeto mankuinhos-r $10 \mathrm{Cl}$ idz. 


\section{ANÁLISE}

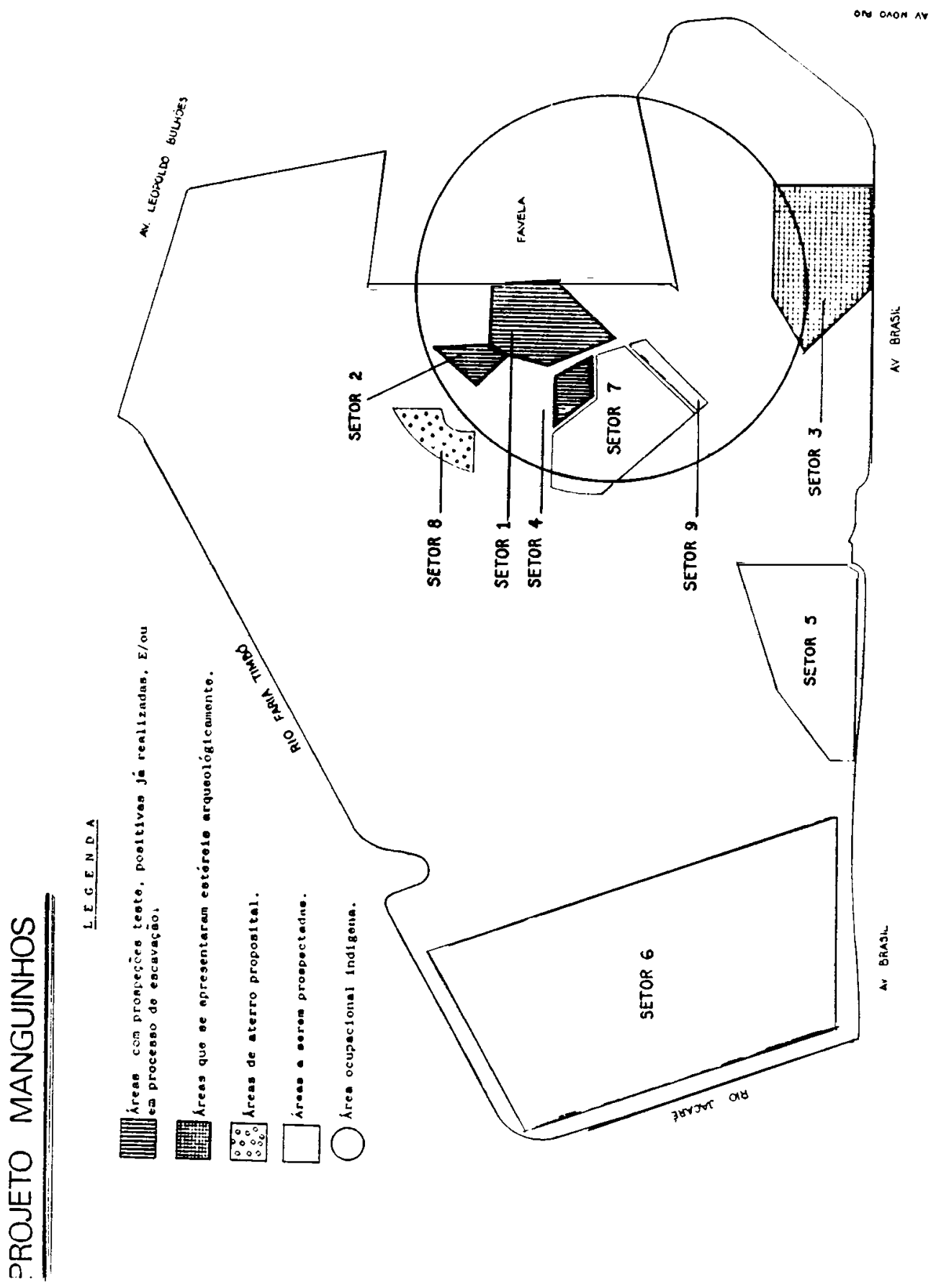


ANÁLISE

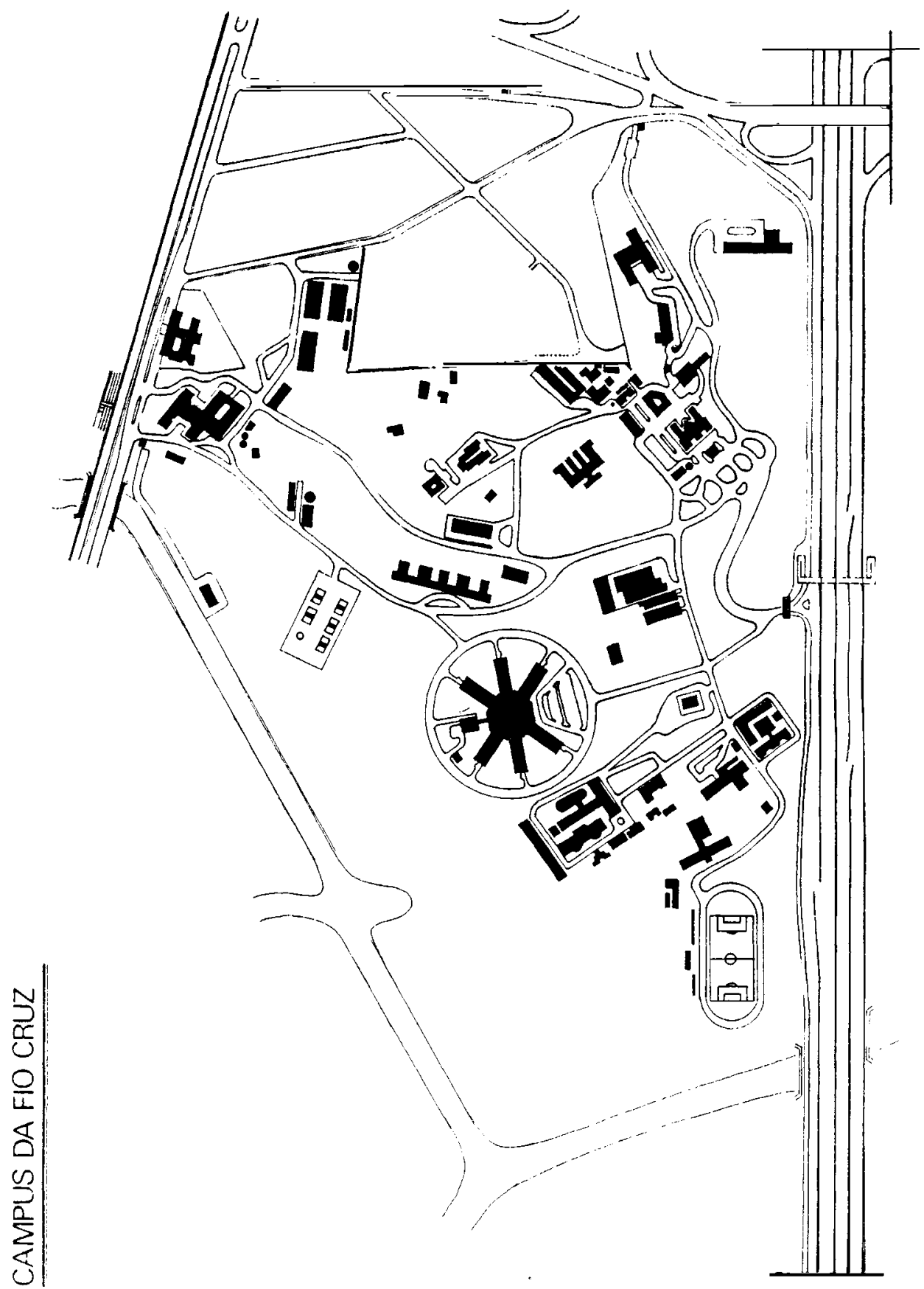

Cadernos de Saúde Pública, RJ, 5 (1): 121-128, jan/mar, 1989 


\section{REFERÊNCIA BIBLIOGRÁFICA}

BELTRĀO, M. C. de M. C. E SARCIÀ, M. N. G. - "L'Industrie lithique et la stratigraphie du Site d'Ttaboraf (Rio de Janeiro, Brésil). In Resumo das Comunicacōes do 2 : Congresso Internationale di Paleontologie Umana (28.09 a 03.10.87) Section $4^{3}$ Homo Erectus - Preneandertallens-Homo Sapiens Archaiques, jp. 174, Torino, Italia, 1987. 